\title{
NUTRIÇÃO MINERAL DE HORTALIÇAS. XXVI - ABSORÇÃO DE MACRO E MICRONUTRIENTES PELO ESPINAFRE (Tetragonia expansa MURR.)*
}

\author{
M.C. THOMAZ** \\ H.P. HAAG *** \\ G.D. DE OLIVEIRA*** \\ J.R. SARRUGE ***
}

\section{RESUMO}

O presente trabalho teve como finalidade, estudar alguns aspectos da nutrição mineral do espinafre (Tetragonia expansa Murr.) no que concerne à composição química e a avaliação das quantidades de nutrientes extraídos e exportados pela cultura, nas diversas etapas de seu desenvolvimento. Para isto foi instalado um experimento de campo usando as práticas culturais normais. Amostragens periódicas foram teitas de acordo com o desenvolvimento das plantas. Conclui-se que:

- a máxima produção de matéria seca das folhas ocorre nos 93 dias e a época de maior exigência corresponde aos 63 dias;

- a época de extração máxima dos nutrientes pelas folhas está entre 93 a 106 dias;

- as quantidades extraídas pela parte aérea aos 90 dias, por ha, são: $\mathrm{N}-39,7 \mathrm{~kg} ; \mathrm{P}-4,7 \mathrm{~kg}$; K- $120,6 \mathrm{~kg}$; Ca- 24,8 kg; Mg- 16,0 kg; S- 5,7 $\mathrm{kg}$; B- $149,4 \mathrm{~g}$; Cu- 34,4 g; Fe- 592,8 g; Mn- 462,2 g; Zn- 147,9 g; Mo- $2,2 \mathrm{~g}$.

\section{INTRODUÇÃO}

As quantidades de nutrientes absorvidas pela cultura em função de sua idade, fornecem informações úteis para a aplicação de fertilizantes. Fica-se conhecendo a quantidade nutrientes absorvidos, a época mais favorável para a aplicação de fertilizante à cultura.

Apesar da grande importância nutricional desta hortaliça em nosso país, são raros os trabalhos visando sua nutrição mineral. Em outros países, referências são encontradas, embora escassas, referindo-se principalmente para o espinafre verdadeiro (Spinacea oleracea L.).Assim, BARADI \& SHAFIE (1963) estudando a absorção de ${ }^{32} \mathrm{P}$ por algumas hortaliças, verificaram que a máxima absorção ocorreu durante o estágio inicial do crescimento para espinafre, recomendado como o melhor período para a aplicação de fertilizantes fosfatados, a 3 ạ semana após o plantio.

* Entregue para publicação em 28/7/1975. Parte da dissertação apresentada peio primciro autor para obtenção do grau de MESTRE pela E.S.A. "Luiz de Queiroz", USP. Apresentado no I Congresso da Sociedade de Olericultura do Brasil, 20 a 26/7/75, Botucatu, SP, Brasil.

* Faculdade de Ciências Agrárias do Pará, Belém, Pará.

** Departamento de Química, E.S.A. "Luiz de Queiroz”, USP, Piracicaba, SP. 
A variação da composição mineral de plantas hortícolas, cultivadas em locais diferentes, quanto ao solo e clima, foi estudada por BEAR et alii (1948), que encontraram teores variando entre $0,27 \%$ a $0,52 \%$ de fósforo, com base na matéria seca, em folhas de espinafre. Valores aproximados a esses, foram obtidos por GERALDSON et alii (1973), em estudo similar.

Estudos sobre o crescimento e absorção de nutrientes pelo espinafre, conduzidos por ZINK (1965), mostraram que $60 \%$ da absorção dos nutrientes ocorreu nos 21 dias que antecederam a colheita, juntamente com a taxa máxima de desenvolvimento da cultura. A composição mineral média da parte aérea das plantas, na época da colheita foi a seguinte: nitrogênio $4,35 \%$; fósforo $0,54 \%$; potássio $6,87 \%$; cálcio $0,95 \%$ e magnésio $0,98 \%$, com base no peso do material seco. Com referência ao enxofre, não se encontrou nenhuma citação na literatura.

BOAWN (1971) estudando a absorção e acúmulo de zinco por algumas hortaliças, cultivadas em solo tratado com níveis de $0 \mathrm{~kg} / \mathrm{ha}$ a $890 \mathrm{~kg} / \mathrm{ha}{ }^{*}$ de zinco, na forma de sulfato de zinco $\left(\mathrm{ZnSO}_{4} \cdot \mathrm{H}_{2} \mathrm{O}\right)$, observou que plantas de espinafre mostraram tendência para acumular zinco. Concentrações do nutriente entre 140 a 340 ppm, nas folhas maduras, foram obtidas pelos autores nos niveis mais baixo e mais alto, ocorrendo uma redução na taxa de desenvolvimento das plantas submetidas ao nivel mais alto do elemento. Folhas de espinafre Nova Zelândia analisadas para ferro, apresentaram em sua composição cerca de $3 \mathrm{mg}$ do elemento por $100 \mathrm{~g}$ de material verde (TASHIRO \& INARI, 1964). Teor semelhante foi encontrado por SCHWIETZER (1963) para espinafre europeu.

Segundo GERALDSON et alii (1973) o teor médio dos micronutrientes, em ppm, encontrado em folhas de espinafre tem uma faixa de oscilação de: 220 a 245 para ferro; 40 a 60 para boro; 5 a 7 para cobre; 50 a 75 para zinco e 30 a 80 para manganês. Estes resultados estão de acordo com os de PETERSON et alii (1945) quanto ao zinco e manganês, mas são menores quanto ao ferro e cobre.

$\mathrm{O}$ presente trabalho foi realizado visando atender o seguinte objetivo: avaliar as quantidades de macronutrientes $(\mathrm{N}, \mathrm{P}, \mathrm{K}, \mathrm{Ca}, \mathrm{Mg}, \mathrm{S})$ e de micronutrientes $(\mathrm{B}, \mathrm{Cu}, \mathrm{Fe}$, $\mathrm{Mn}, \mathrm{Zn}$ e Mo) extraidas e exportadas pela cultura, nas diversas etapas de seu desenvolvimento.

\section{MATERIAIS E MÉTODOS}

O experimento foi instalado em solo com mais de vinte anos de cultivo, principalmente com hortaliças, cujas características químicas determinadas segundo CATANI \& JACINTHO (1974), encontram-se no Quadro 1.

* Dados recalculados. 
QUADRO 1 - Características químicas do solo utilizado no ensaio.

\begin{tabular}{ccccccccc}
\hline pH & $\begin{array}{c}\text { Matéria } \\
\text { orgânica } \\
\%\end{array}$ & $\begin{array}{c}\mathrm{PO}_{4}^{3-} \\
\text { solúvel }\end{array}$ & $\mathrm{K}+$ & $\mathrm{Ca}^{2}+$ & $\begin{array}{c}\mathrm{Mg}^{2}+ \\
\text { trocável }\end{array}$ & $\mathrm{H}^{+}$ & $\mathrm{Al}^{3+}$ \\
\hline & 1,20 & 0,18 & 0,30 & 3,97 & 1,63 & 4,86 & 0,21 \\
\hline
\end{tabular}

Após o preparo conveniente do canteiro, procedeu-se a uma prévia adubação, com esterco de gado na base de $8 \mathrm{~kg}$ por metro quadrado, $30 \mathrm{~g}$ de superfosfato triplo (45\% $\left.\mathrm{P}_{2} \mathrm{O}_{5}\right)$ e $10 \mathrm{~g}$ de cloreto de potássio $\left(60 \% \mathrm{~K}_{2} \mathrm{O}\right)$ por metro quadrado. $\mathrm{O}$ nitrogênio, na forma de salitre do Chile $(16 \% \mathrm{~N})$, foi aplicado em cobertura, na oase de $8 \mathrm{~g}$ por metro quadrado, aos 15 dias, 30 dias e 45 dias após o transplante, em partes iguais (Bernardi, 1970, citado por SILVEIRA et alii, 1971).

Oito dias depois da adubação, foram transplantadas as mudas, com aproximadamente um mês de idade, no espaçamento de $0,90 \mathrm{~m}$ x $0,50 \mathrm{~m}$, segundo recomendações de FILGUEIRA (1972).

As plantas foram coletadas sempre ao acaso, em número nunca inferior a quatro, ocorrendo a primeira amostragem por ocasião do transplante e as demais a intervalos regulares, em funçăo do desenvolvimento das plantas. Dados relativos ao número, data e época das amostragens, ao número de plantas colhidas em cada amostragem e seu estádio de desenvolviemento foram agrupados no Quadro 2.

QUADRO 2 - Idade, estádio de desenvolvimento, número de plantas colhidas e data das amostragens.

\begin{tabular}{clcc}
$\begin{array}{c}\text { Iáade } \\
\text { após a } \\
\text { germinação }\end{array}$ & $\begin{array}{c}\text { Estádio de } \\
\text { desenvolvimento }\end{array}$ & $\begin{array}{c}\text { Número de plantas } \\
\text { colhidas por } \\
\text { amostragem }\end{array}$ & $\begin{array}{c}\text { Data das } \\
\text { imostragens }\end{array}$ \\
\hline \hline 30 & Transplante & 126 & 18.08 .73 \\
45 & - & 38 & 02.09 .73 \\
60 & Início de floração & 9 & 17.09 .73 \\
75 & Floração & 5 & 02.10 .73 \\
90 & Frutificação & 4 & 17.10 .73 \\
105 & - & 4 & 01.11 .73 \\
120 & - & 4 & 16.11 .73 \\
\hline
\end{tabular}

Após a coleta, as plantas foram submetidas à lavagem rápida com solução de detergente ${ }^{\star}$ a, aproximadamente, $0,1 \%$, depois com água destilada e por fim com água desmineralizada; separadas em folhas, caules e frutos; pesadas separadamente e finalmente submetidas à secagem e análise química de acordo com os métodos descritos em SARRUGE \& HAAG (1974).

$\overline{\text { * Alconox, fabricação de Alconox Inc. N. York, USA. }}$ 
RESULTADOS E DISCUSSĀO

\section{Crescimento}

O desenvolvimento das plantas foi estudado através dos dados de produção de matéria seca dos órgãos, de acordo com as épocas de amostragem.

A análise de variância da produção de matéria seca das folhas, caule e frutos, em função da idade da planta, mostrou que o efeito da interação idades x partes da planta foi significativo, indicando o comportamento diferente dos órgãos em relação às diversas idades. Em vista disso, efetuou-se o desdobramento, através das análises de regressão linear, quadrática e cúbica das diferentes idades dentro de cada órgão da planta. A escolha das regressões para a explicação desse fato, além da coerência com a realidade, baseou-se na significância da regressão de maior grau e no maior coeficiente de determinação. Assim, as folhas obedeceram a regressão cúbica e o caule e os frutos tiveram efeito linear.

Os parâmetros das equações de regressão permitiram a representação gráfica das curvas de crescimento dos órgãos (Figura 1) onde a variável $\mathbf{x}$ expressa as idades, em dias e $\hat{\mathbf{y}}$ os teores de matéria seca em grama por planta.

Examinando-se a curva de crescimento das folhas (Figura 1), observa-se que o aumento da matéria seca foi bem lento até os 60 dias, acentuando-se, a partir daí. Apenas cerca de $13 \%$ desse material, foi produzido até a metade do periodo de desenvolvimento das plantas.

ZINK (1965), trabalhando com espinafre, relata que somente $9 \%$ de matéria seca foi produzida nessa etapa do desenvolvimento.

Na faixa dos 60 a 75 dias ocorreu um aumento de mais de $50 \%$ de matéria seca nas folhas, em comparação com o valor máximo.

Através da equação de 3 ? grau obtida para as folhas, calculou-se os pontos de inflexão e de máxima da curva. $O$ ponto de inflexão, determinado aos 63 dias, indicou essa época como a maior exigência da cultura. A partir desse ponto, os acréscimos na quantidade de matéria seca das folhas foram se tornando menores até anular-se, onde a produção foi máxima.

O ponto de máxima da curva ocorreu aos 93 dias, significando que nessa época, a produção de matéria seca das folhas foi máxima.

$\mathrm{O}$ decréscimo acentuado no ritmo de crescimento das folhas com redução de seu peso de matéria seca, observado aos 105 dias, pode ser atribuído à queda das folhas, abundante nesse período, e ainda à translocação de compostos para os frutos, como decorrência do processo de senescência da planta.

COSTA et alii (1972) e FERNANDES et alii (1972) fizeram observações semelhantes em plantas de quiabo e cravo. SARRUGE et alii (1963) trabalhando com algodoeiro verificaram também queda de galhos mais velhos, além das folhas, com redução acentuada do peso do material seca.

A produção de matéria seca do caule e dos frutos, teve um aumento contínuo até a 
última amostragem. Por ocasião do término do período experimental a translocação de produtos fotossintetizados para os frutos processava-se ainda, justificando a linearidade das curvas de crescimento do caule e dos frutos (Figura 1).

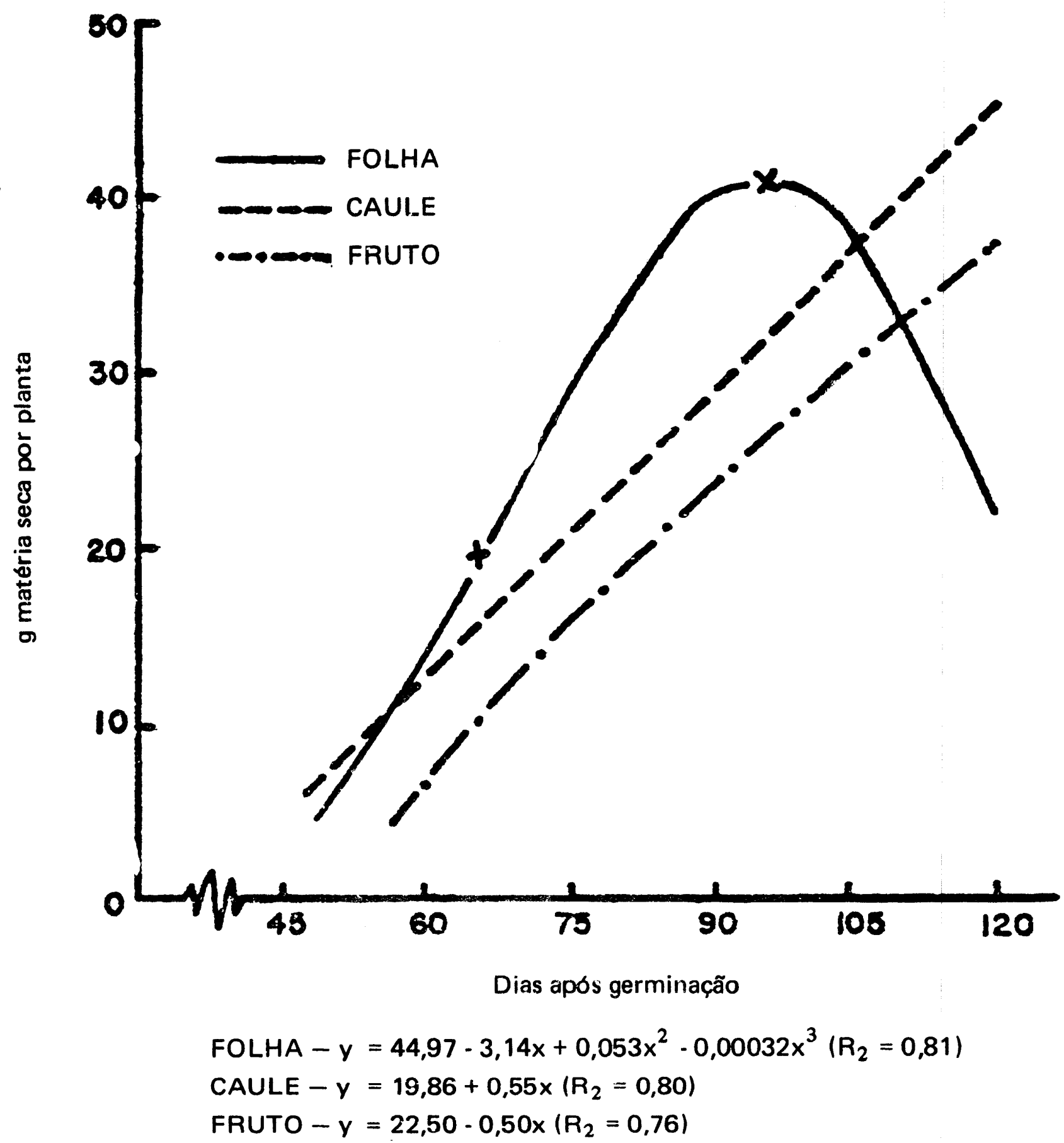

FIG. 1 - Produção de matéria seca, em função do estádio de desenvolvimento da planta. $\left(\mathbf{R}_{2}=\right.$ coeficiente de determinação $)$.

A correlação positiva observada entre a quantidade de matéria seca das folhas, caule e frutos e as diferentes idades, foi significativa ao nivel de $1 \%$ de probabilidade.

Trabalhando com feijoeiro, COBRA NETTO et alii (1971), encontraram também correlação semelhante entre o peso de matéria seca e a idade das plantas.

Curvas de crescimento de plântulas de melão cultivadas em diferentes temperaturas, em função da idade, ajustadas aos dados experimentais obtiđ̧os por PEARL et alii 
(1934) são concordantes com a curva obtida para as folhas.

Alguns dos resultados obtidos por GOODALL (1946) com plantas de tomate, em estudos de correlação e de regressão envolvendo a variação da produção de matéria seca e outras variáveis, como taxa de translocação e temperatura, em função de diferentes épocas, concordam, de um modo geral, com os do presente trabalho.

O desenvolvimento da cultura está muito ligado a fatores ambientais, principalmente climáticos. Segundo KNOTT (1950), chuvas ou irrigação, temperatura entre $20{ }^{\circ} \mathrm{C}$ a $24{ }^{\circ} \mathrm{C}$ e umidade relativa do ar entre $50 \%$ e $80 \%$ são requeridos para urr hom desenvolvimento e produção. Os dados metereológicos médios observados durante o periodo experimental (Quadro 3), mostram que a época de maior queda pluviométrica, ocorrida em outubro, coincidiu com a da produção máxima de matéria seca. Os outros dados estão, também, dentro da faixa considerada satisfatória para a cultura.

Em ensaios conduzidos por ZINK (1965), com espinafre, a oscilação observada pelo autor na quantidade de matéria seca durante o desenvolvimento das plantas foi associada a programa de irrigação.

QUADRO 3 - Elementos metereológicos.do 20 semestre do ano agrícola de 1973. Município de Piracicaba.

\begin{tabular}{lccccc}
\hline \multicolumn{1}{c}{$\begin{array}{c}\text { Dados } \\
\text { meteorológicos }\end{array}$} & julho & agosto & setembro & outubro & novembro \\
\cline { 2 - 5 } & 60 & 19 & 55 & 175 & 122 \\
\hline $\begin{array}{l}\text { Total de precipitação } \\
\text { mensal (mm) }\end{array}$ & 16,8 & 17,6 & 20,6 & 21,1 & 21,5 \\
$\begin{array}{l}\text { Temperatura média } \\
\left.\text { do ar ( }{ }^{\circ} \mathrm{C}\right)\end{array}$ & 76 & 72 & 74 & 71 & 70 \\
$\begin{array}{l}\text { Média de umidade } \\
\text { relativa do ar }(\%)\end{array}$ & 76 & & & & \\
\hline
\end{tabular}

Fonte: Departamento de Física e Meteorologia da Escola Superior de Agricultura "Luiz de Queiroz", USP, Piracicaba - SP.

\section{Concentração de nutrientes}

As análises químicas da matéria seca das diversas amostras permitiram se obter os teores médios dos macronutrientes e dos micronutrientes nas folhas, caule e frutos, em função do estádio de desenvolvimento da planta.

A análise da variância do efeito das idades sobre a quantidade de nutrientes nos órgãos em estudo mostrou que o efeito da interação idades $x$ partes da planta só não foi significativo para o boro, revelando que os órgãos comportaram-se semelhantemente nas diferentes idades, quanto a este nutriente.

O desdobramento da análise da variância foi feito através das análises de regressão linear, quadrática e cúbica das diferentes idades dentro de cada órgão da planta. Foram adotadas regressões, cúbica para explicar o fenômeno nas folhas, linear para os frutos e, dependendo do nutriente, regressão linear, quadrática ou cúbica para o caule. 
As curvas de absorçăo dos nutrientes foram obtidas através das equações de regressão, em cuja representação gráfica a variável $\mathbf{x}$ expressa as idades em dias, e a $\hat{\mathbf{y}}$ a quantidade dos macronutrientes, em miligrama, e dos micronutrientes, em micrograma.

Os pontos de máxima e de inflexão das curvas foram determinados, a fim de se conhecer as épocas de maior extração dos nutrientes e a de maior exigência dos órgãos nesses nutrientes.

\section{Macronutrientes}

De um modo geral, a absorção desses nutrientes pelos órgãos em estudo, seguiu efeito cúbico para as folhas e linear para os frutos.

Observa-se pela Figura 2 que a absorção do nitrogênio, do cálcio, do magnésio e do enxofre pelo caule teve efeito linear.

Inicialmente, a quantidade desses nutrientes nas folhas mostrou-se baixa, aumentando gradualmente até a faixa dos 94 a 106 dias, quando ocorreu a extração máxima desses nutrientes, segundo o ponto de máxima determinado para as curvas de absorção. A partir daí se observou o decréscimo da quantidade até o final do experimento, como decorrência do processo de translocação dos nutrientes para outros órgãos. 


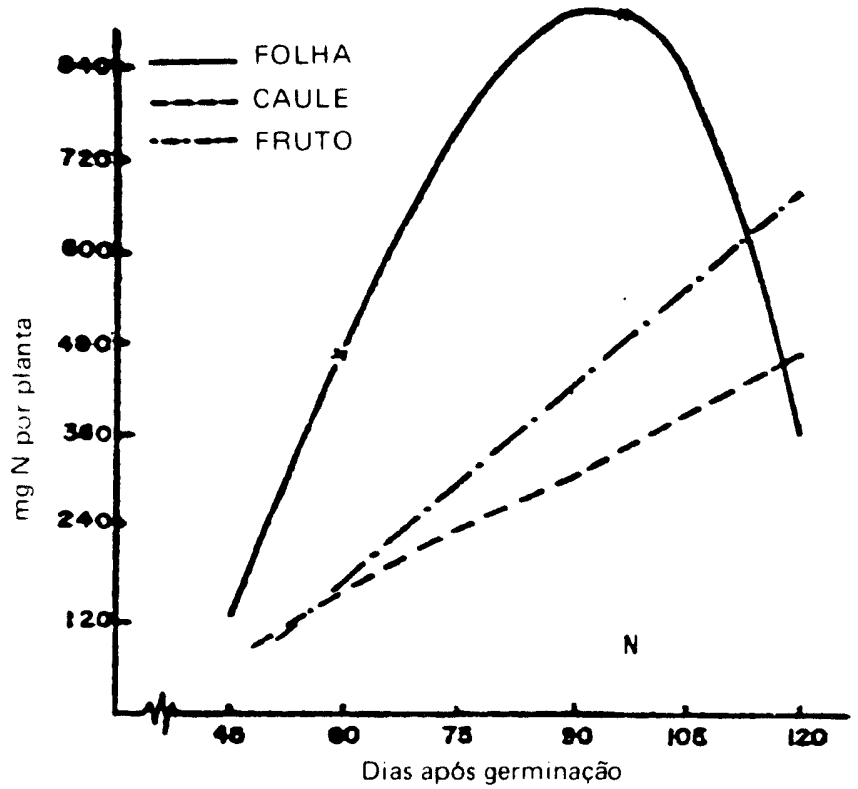

FOLHA $-y=425,04 \cdot 42,95 x+1,09 x^{2} \cdot 0,006 x^{3}\left(R_{2}=0,66\right.$

CAULE - $V=171,61+5,24 \times\left(R_{2}=0,70\right)$

FRUTC $-y=388,13+8,914 \times\left(R_{2}=0,77\right)$

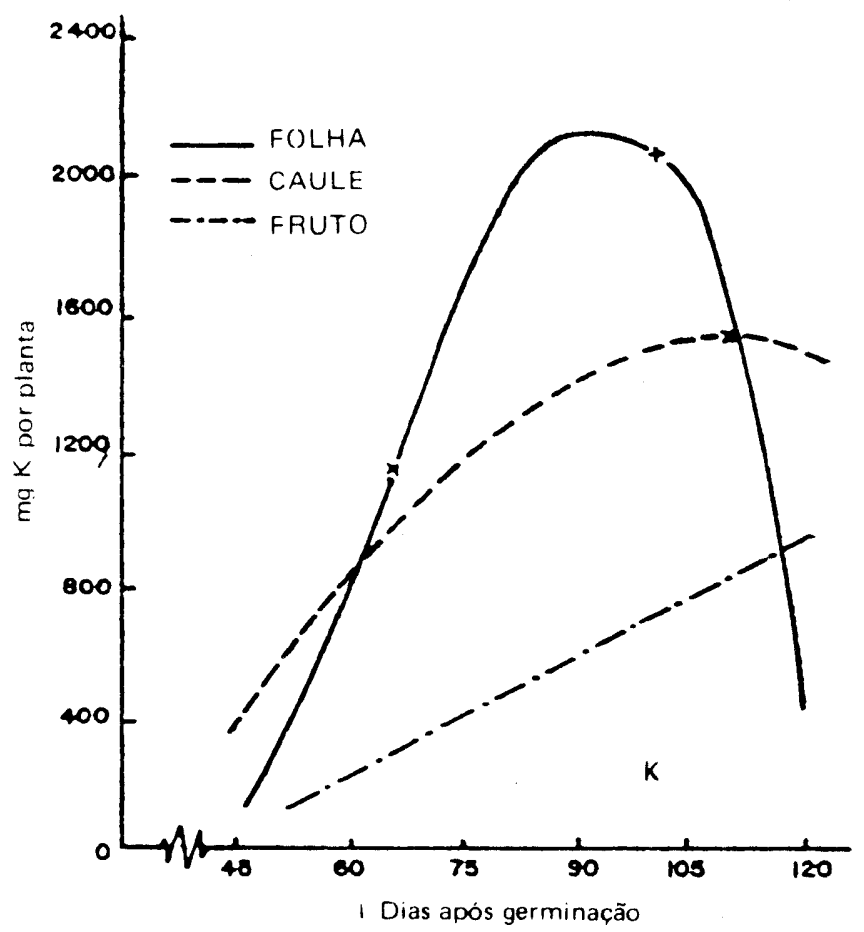

FOLHA $-Y=2958,94 \cdot 206,22 x+4,16 x^{2} \cdot 0,021 x^{3}\left(R_{2}=0,74\right)$ CAULE $-y=1991,37+64,38 x \cdot 0,29 x^{2}\left(R_{2}=0,65\right)$

FRUTO $y=-520,56+12,32 \times\left(R_{2}=0,74\right)$

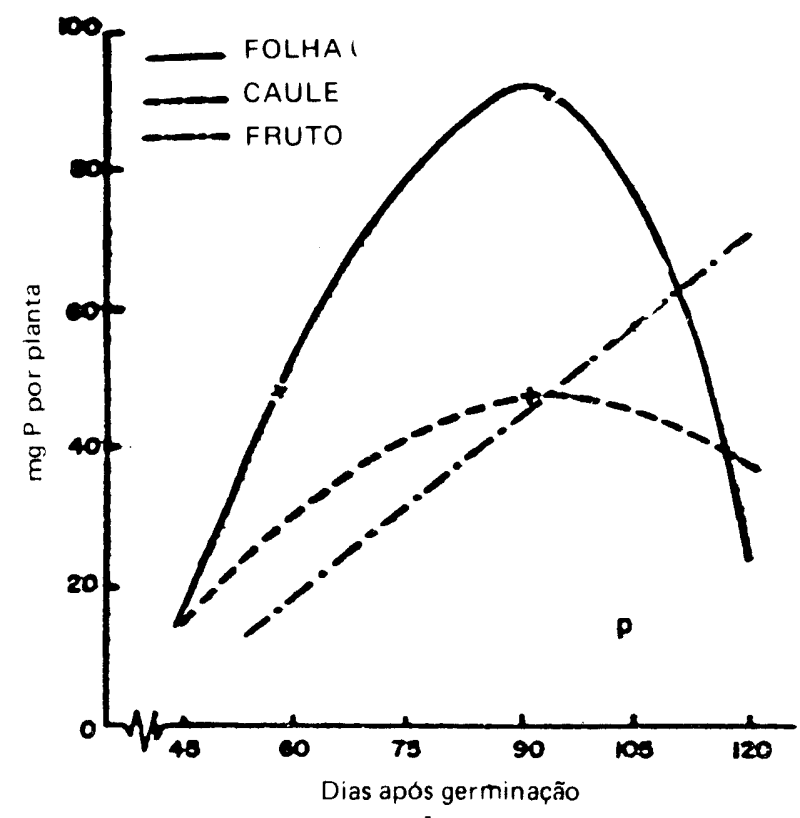

FOLHA $-y=32,25 \cdot 4,05 x+0,11 x^{2} \cdot 0,00064 x^{3}\left(R_{2}=0,65\right)$

CAULE - $y=78,98+2,61 x \cdot 0,014 x^{2}\left(R_{2}=0,61\right)$

FRUTO - $y=34,95+0,88 \times\left\{R_{2}=0,64\right\}$

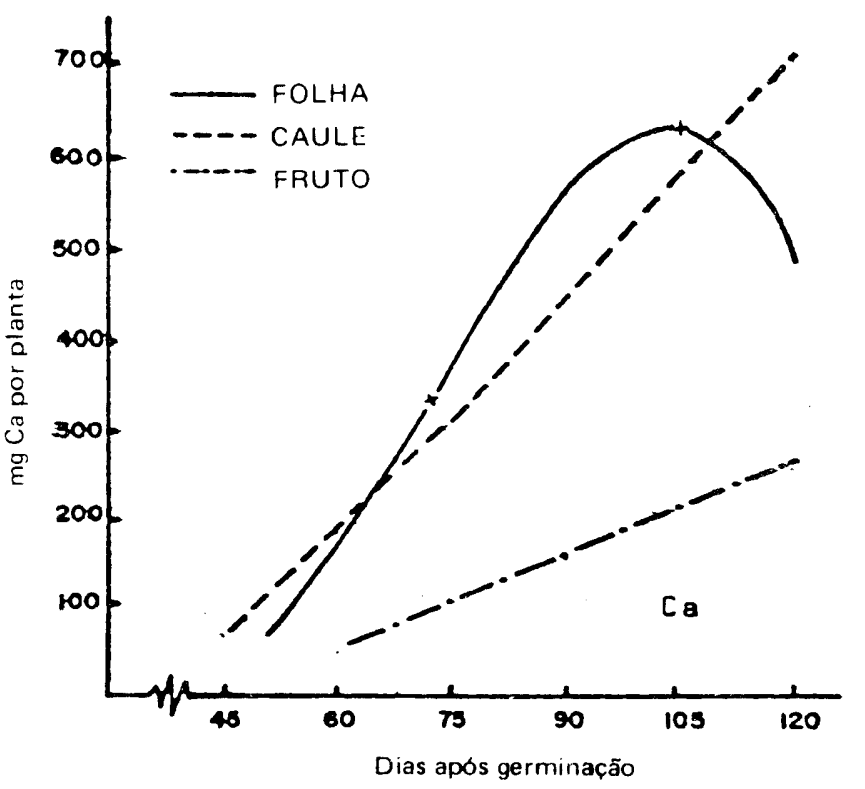

FOLHA - y $=730,12 \cdot 47,36 x+0,89 x^{2} \cdot 0,0042 x^{3}\left(R_{2}=0,81\right)$ CAULE - $y=-308,73+8,42 \times\left(R_{2}=0,84\right)$ FRUTO $-y=-136,70+3,27 \times\left(R_{2}=0,73\right)$

FIG. 2 - Absorção dos macronutrientes, em miligrama, em função do estádio de desenvolvimento da planta. 

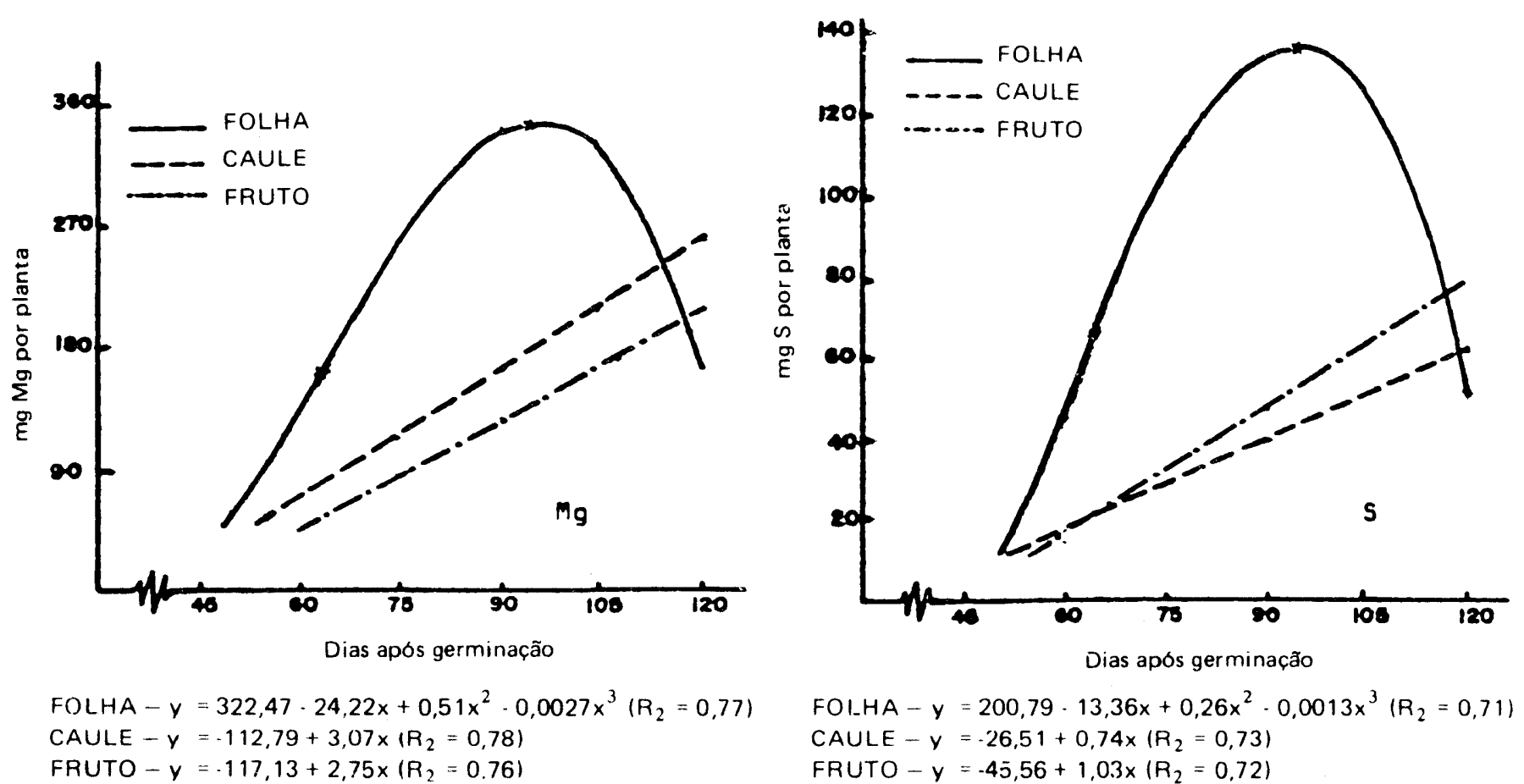

FOI.HA - y $=200,79 \cdot 13,36 x+0,26 x^{2} \cdot 0,0013 x^{3}\left(R_{2}=0,71\right)$

CAULE-y $=.26,51+0,74 x\left(R_{2}=0,73\right)$

FRUTO $-y=-45,56+1,03 x\left(R_{2}=0,72\right)$

FIG. 2 - Absorção dos macronutrientes, em miligrama, em função do estádio de desenvolvimento da planta.

$\mathrm{Na}$ faixa de 60 a 75 dias, correspondente ao ponto de inflexão das curvas, ocorreu a maior exigência das folhas nesses nutrientes. A partir desse período os acréscimos na quantidade total dos nutrientes foram se tornando menores até anular-se no ponto onde a extração foi máxima. Pelo esquema a seguir, observa-se os pontos de inflexão e de máxima de cada nutriente.

\begin{tabular}{|c|c|c|}
\hline \multirow{2}{*}{ Nutriente } & \multicolumn{2}{|c|}{ Dias } \\
\hline & Ponto de inflexão & Ponto de máxima \\
\hline nitrogênio & 60 & 96 \\
\hline cálcio & 71 & 106 \\
\hline magnésio & 64 & 95 \\
\hline enxofre & 64 & 94 \\
\hline
\end{tabular}

Em relação à quantidade máxima de nutrientes absorvida no período dos 96 dias, 106 dias, 95 dias e 94 dias para o nitrogênio, cálcio, magnésio e enxofre, respectivamente, pode-se avaliar a quantidade deles, em percentagem, absorvida pelas folhas na época de maior exigência desse órgão, conforme segue no quadro.

ZINK (1965), trabalhando com espinafre, verificou que a taxa máxima de extı ção dos nutrientes se deu durante os 21 dias imediatamente precedentes à colheita, ocorrida a partir dos 75 dias.

No caule e nos frutos a concentração dos nutrientes também foi baixa inicialmente, aumentando progressivamente até a última amostragem. O processo de translocação desses nutrientes para os frutos pode ser uma explicação para o aumento contínuo nas 
concentrações dos nutrientes durante o periodo experimental, justificando a tendência linear tomada pelas curvas de absorção dos nutrientes nesses órgãos.

\begin{tabular}{lcc} 
& Dias & $\frac{\%}{n}$ \\
\cline { 3 - 3 } Nutriente & $\begin{array}{c}\text { Época de maior } \\
\text { exigência }\end{array}$ & $\begin{array}{c}\text { Quantidade absorvida } \\
\text { em relação à máxima }\end{array}$ \\
\hline \hline nitrogênio & 60 & 44 \\
cálcio & 71 & 50 \\
magnésio & 64 & 50 \\
enxofre & 64 & 43 \\
\hline
\end{tabular}

A absorção do fósforo e do potássio pelas folhas (Figura 2) foi semelhante a dos macronutrientes já descritos, com o período de extração máxima, determinado nas curvas, entre 94 e 99 dias, a partir do qual ocorreu o decréscimo na quantidade absorvida até a última amostragem, de modo idêntico ao observado para os outros. A época de maior exigência das folhas nos nutrientes, foi observada entre 58 e 66 dias para o fósforo e potássio, respectivamente. Os pontos de inflexão e de máxima dos nutrientes foram:

\begin{tabular}{lccc}
\hline \multirow{2}{*}{ Nutriente } & \multicolumn{2}{c}{ Dias } \\
\cline { 2 - 3 } & Porto de inflexão & Ponto de média \\
\hline \hline fósforo & 58 & 94 \\
potássio & 66 & 99 \\
\hline
\end{tabular}

As quantidades de fósforo e potássio absorvidas na época de maior exigência das folhas, expressas em percentagem do máximo encontrado, podem ser vistas a seguir:

\begin{tabular}{|c|c|c|}
\hline \multirow[b]{2}{*}{ Nutriente } & Dias & $\%$ \\
\hline & $\begin{array}{l}\text { Época de maior } \\
\text { exigência }\end{array}$ & $\begin{array}{l}\text { Quantidade absorvida } \\
\text { em relação à máxima }\end{array}$ \\
\hline $\begin{array}{l}\text { fósforo } \\
\text { potássio }\end{array}$ & $\begin{array}{l}58 \\
66\end{array}$ & $\begin{array}{l}47 \\
49\end{array}$ \\
\hline
\end{tabular}

Com respeito ao caule, a curva de absorção de fósforo e potássio obedeceu à regressão quadrática. Possivelmente a taxa de transiocação desses nutrientes no caule sofreu um decréscimo após a faixa dos 90 dias, para fósforo e 111 dias para o potássio, ocasionando o efeito de 2 ọ grau das curvas de absorção.

Os pontos de máxima calculados para as curvas mostraram que a época de maior extração do fósforo pelo caule foi a dos 90 dias e do potássio, 111 dias.

A curva de absorção para os frutos, seguiu o mesmo efeito dos macronutrientes, vistos anteriormente.

De um modo geral, as folhas, caules e frutos apresentaram teores mais elevados de potássio, nitrogênio e cálcio e os mais baixos de enxofre e fósforo. As diferenças 
na concentração dos nutrientes, observadas entre as amostragens iniciais e as posteriores são explicadas pela diluição desses nutrientes motivada pelo desenvolvimento bastante rápido das plantas (Quadro 4).

QUADRO 4 - Teores percentuais dos macronutrientes contidos na matéria seca dos órgãos estudados, em função da idade da planta.

\begin{tabular}{|c|c|c|c|c|c|c|c|}
\hline \multirow{2}{*}{$\begin{array}{l}\text { Idade da } \\
\text { planta } \\
\text { (dias) }\end{array}$} & \multirow[b]{2}{*}{ Órgão } & \multicolumn{6}{|c|}{ Nutrientes } \\
\hline & & $\mathbf{N}$ & $\mathbf{P}$ & $\mathbf{K}$ & $\mathrm{Ca}$ & $\mathrm{Mg}$ & $S$ \\
\hline \multirow{3}{*}{30} & folha & 3,94 & 0,37 & 0,30 & 0,66 & 0,90 & 0,40 \\
\hline & caule & 1,88 & 0,37 & 6,99 & 1,24 & 0,47 & 0,32 \\
\hline & fruto & - & - & - & - & - & - \\
\hline \multirow{3}{*}{45} & folha & 3,62 & 0,42 & 5,58 & 0,87 & 0,79 & 0,41 \\
\hline & caule & 1,58 & 0,30 & 4,59 & 1,02 & 0,45 & 0,27 \\
\hline & fruto & - & - & - & - & - & - \\
\hline \multirow{3}{*}{50} & folha & 3,77 & 0,32 & 5,00 & 1,00 & 0,96 & 0,24 \\
\hline & caule & 1,74 & 0,28 & 6,77 & 1,93 & 0,67 & 0,16 \\
\hline & fruto & 3,09 & 0,42 & 4,76 & 0,99 & 0,96 & 0,32 \\
\hline \multirow{3}{*}{75} & folha & 2,93 & 0,33 & 5,39 & 1,52 & 0,98 & 0,35 \\
\hline & caule & 1,11 & 0,22 & 5,45 & 1,70 & 0,57 & 0,15 \\
\hline & fruto & 2,28 & 0,40 & 3,55 & 1,19 & 0,91 & 0,27 \\
\hline \multirow{3}{*}{90} & folha & 2,54 & 0,21 & 5,64 & 1,06 & 0,83 & 0,35 \\
\hline & caule & 1,07 & 0,15 & 5,06 & 1,12 & 0,47 & 0,13 \\
\hline & fruto & 2,06 & 0,29 & 3,44 & 0,75 & 0,70 & 0,24 \\
\hline \multirow{3}{*}{105} & folha & 2,21 & 0,18 & 4,68 & 2,25 & 0,83 & 0,30 \\
\hline & caule & $1, n 1$ & 0,09 & 3,49 & 1,78 & 0,60 & 0,12 \\
\hline & fruto & 1,80 & 0,18 & 2,48 & 0,76 & 0,53 & 0,21 \\
\hline \multirow{3}{*}{120} & folha & 1,82 & 0,14 & 3,71 & 1,96 & 0,81 & 0,26 \\
\hline & caule & 0,92 & 0,09 & 3,44 & 1,58 & 0,61 & 0,12 \\
\hline & fruto & 1,74 & 0,15 & 2,25 & 0,60 & 0,54 & 0,20 \\
\hline
\end{tabular}

ZINK (1965), em estudo com espinafre, HOMA et alii (1969) com couve-flor e FERNANDES et alii (1971) com alface, encontraram resultados concordantes, quanto à concentração de macronutrientes nessas hortaliças.

\section{Micronutrientes}

As curvas de absorção do cobre, do manganês e do zinco pelos órgãos em estudo são semelhantes quanto à tendência seguida: cúbica para as folhas e caule e linear para os frutos, conforme pode ser visto na Figura 3. 


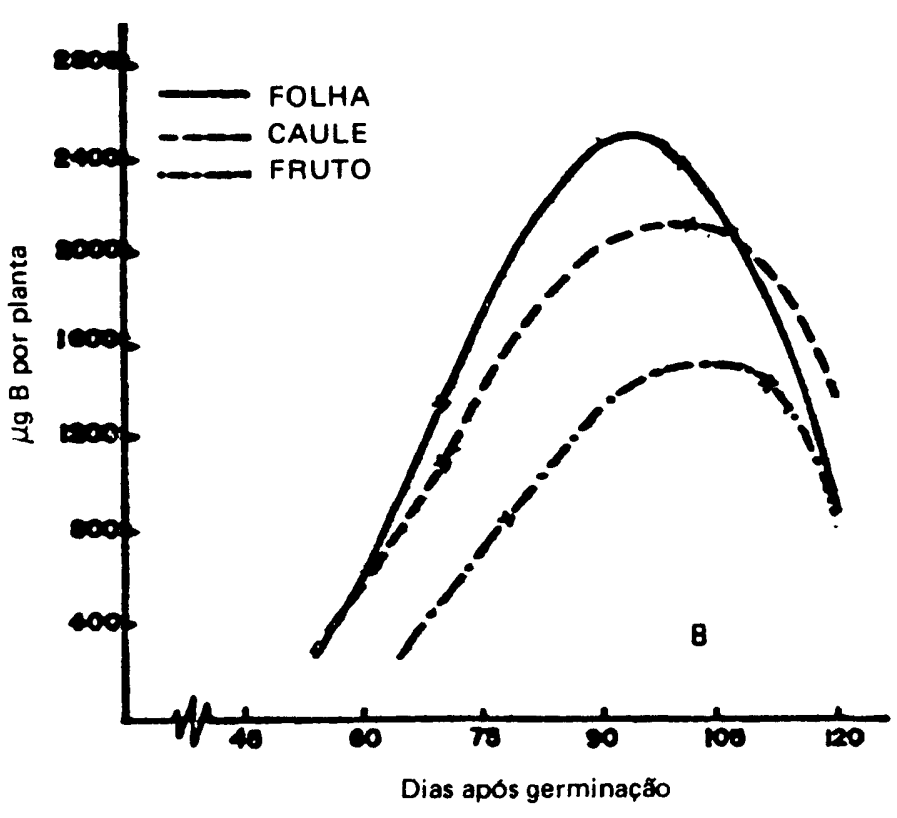

FOLHA $-y=5284,27-324,58 x+5,84 x^{2} \cdot 0,028 x^{3}\left(R_{2}=0,61\right)$ CAULE - $y=2897,66 \cdot 189,40 x+3,56 x^{2} \cdot 0,017 x^{3}\left(R_{2}=0,71\right)$ FRUTO $-y=5003,92-276,54 x+4,42 x^{2}-0,019 x^{3}\left(R_{3}=0,33\right)$

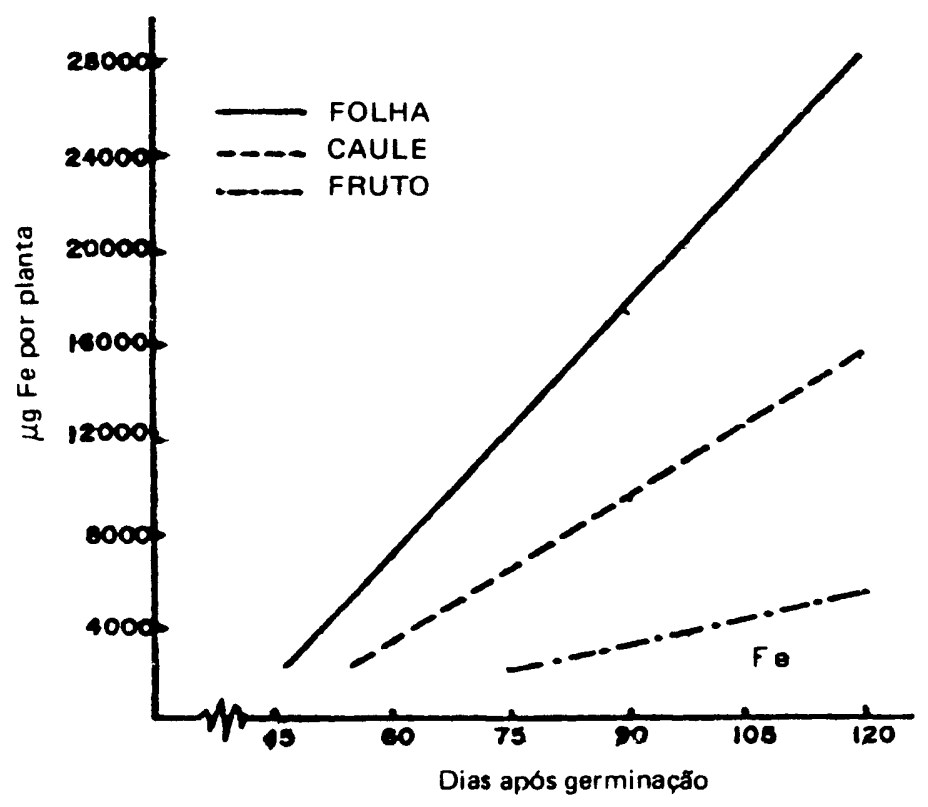

FOLHA $-y=-14145,74+361,65 \times\left(R_{2}=0,74\right)$

CAULE $-y=8163,00+196,22 \times\left(R_{2}=0,56\right)$

FRUTO $-y=-3013,34+68,95 \times\left(R_{2}=0,59\right)$

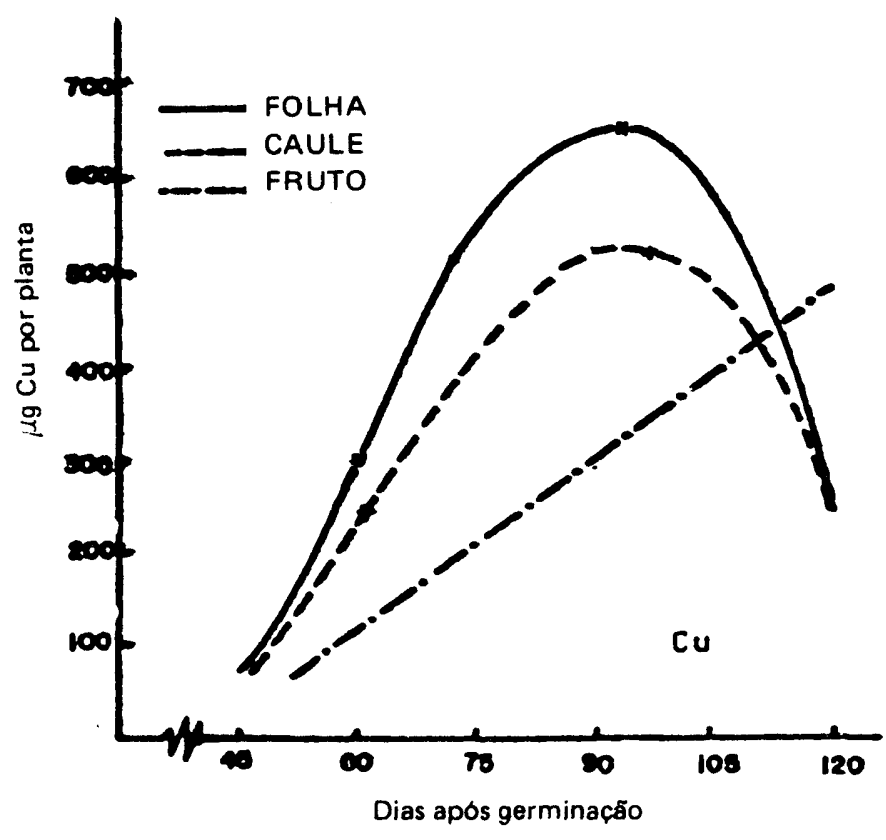

FOLHA $-y=472,65 \cdot 39,90 x+0,91 x^{2}-0,0049 x^{3}\left(R_{2}=0,65\right)$ CAULE - $y=304,78-28,48 x+0,67 x^{2}-0,0037 x^{3}\left(R_{2}=0,51\right)$ FRUTO $-y=-257,81+6,10 \times\left(R_{2}=0,72\right)$

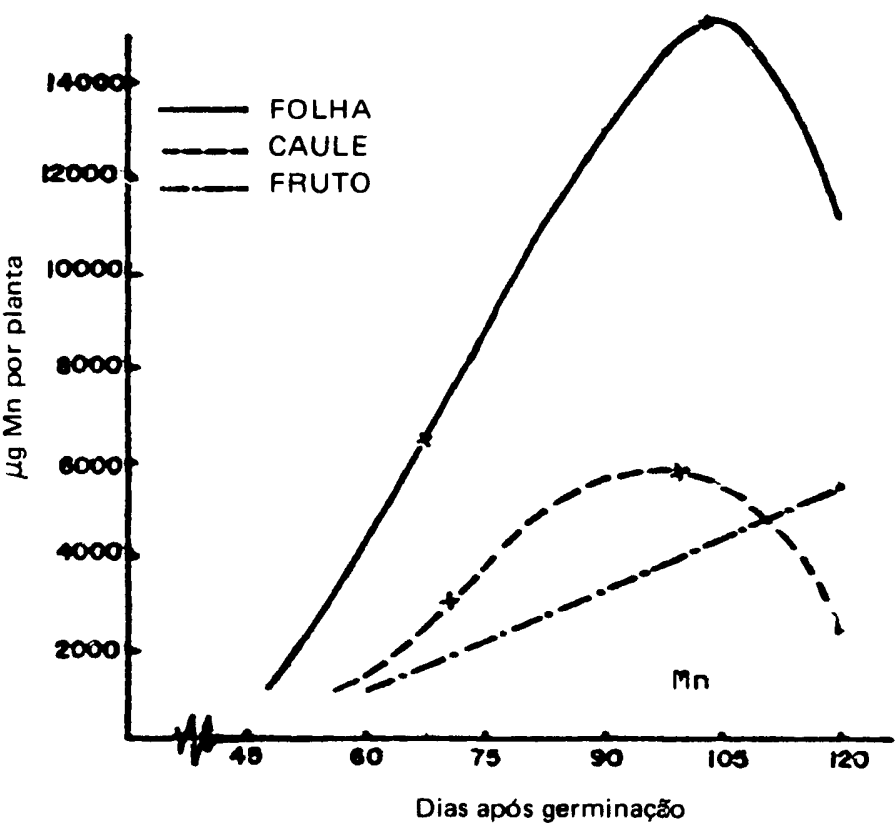

FOLHA $-y=10655,90-802,73 x+16,69 x^{2} \cdot 0,083 x^{3}\left(R_{2}=0,74\right)$ CAULE $-y=17742.05-724,33 x+13,05 x^{2}-0,063 x^{3}\left(R_{2}=0,52\right)$ FRUTO $-y=-3013,34+68,94 \times\left(R_{2}=0,59\right)$

FIG. 3 - Absorção dos micronutrientes, em micrograma, em função do estádio de desenvolvimento da planta. 


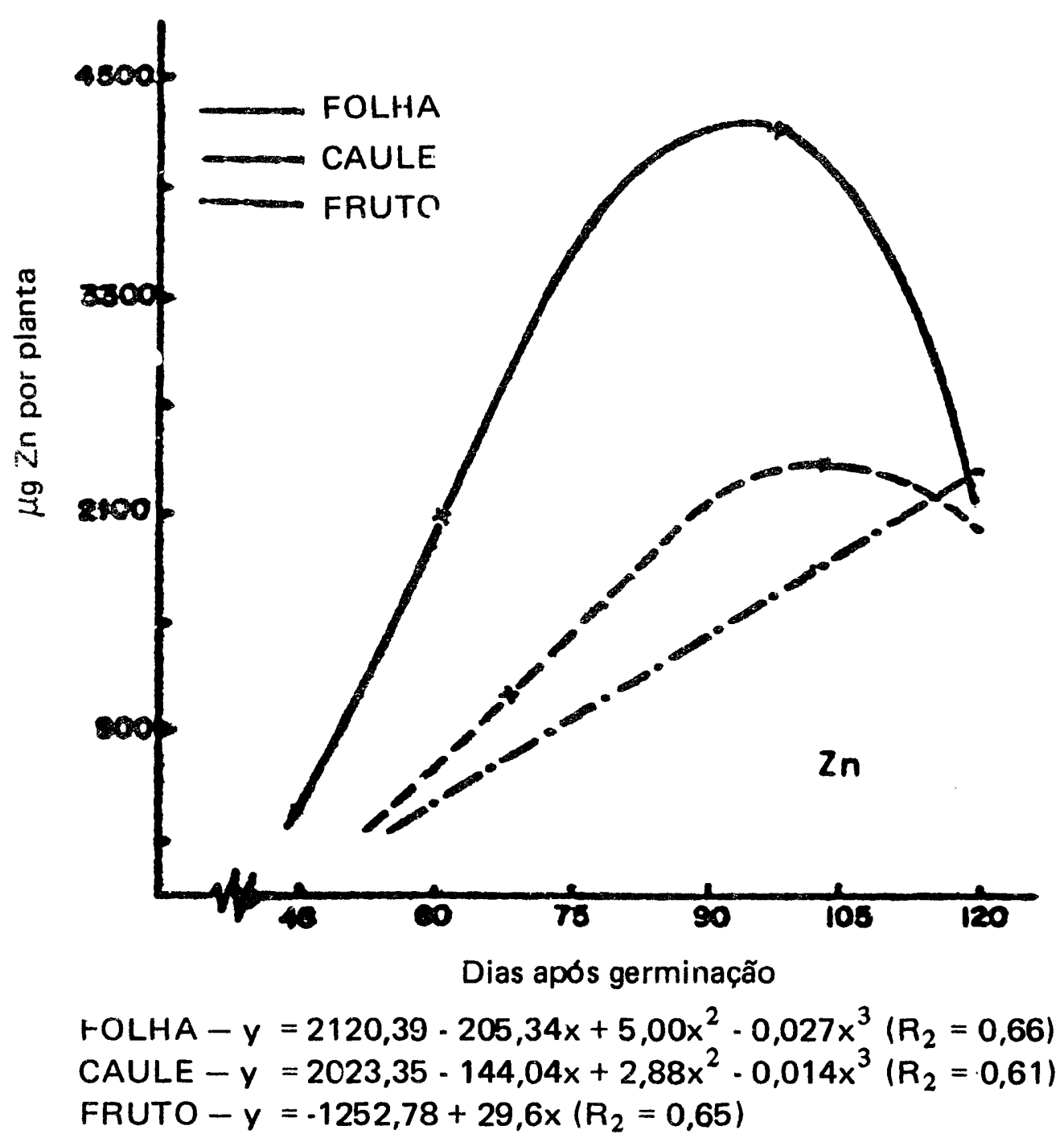

FIG. 3 - Absorção dos micronutrientes, em micrograma, em função do estádio de desenvolvimento da planta.

A quantidade desses nutrientes absorvida pelas folhas e caule foi também pequena no início, aumentando progressivamente até a faixa máxima de extração, calculada entre os 93 dias a 104 dias. A partir desse período, observou-se o decréscimo da quantidade dos nutrientes nesses órgãos até a última amostragem. $O$ processo de translocação desses nutrientes para os frutos deve ter sido intenso também no caule, ocasionando o decréscimo observado, após a extração máxima.

$\mathrm{O}$ ponto de inflexão das curvas também determinado indicou a época dos 61 dias a 69 dias como a de maior exigência dos órgãos resses nutrientes.

\begin{tabular}{lcccrr}
\hline \multirow{2}{*}{ Nutriente } & \multicolumn{2}{c}{ Ponto de inflexão } & & \multicolumn{2}{c}{ Ponto de máxima } \\
\cline { 2 - 5 } & folhas & caule & & folhas & caule \\
\cline { 2 - 5 } & & & Dias & & 96 \\
cobre & 61 & 61 & 93 & 104 & 100 \\
manganês & 67 & 69 & 97 & & 104 \\
zinco & 62 & 68 & & &
\end{tabular}


Atribuindo-se o valor 100 ao teor máximo absorvido no período de 93 a 104 dias é possivel avaliar as quantidades de cobre, manganês e zinco absorvidas na época de maior exigência das folhas e do caule.

\begin{tabular}{llcc}
\hline Nutriente & Órgão & $\begin{array}{c}\text { Dias } \\
\text { Epoca de maior } \\
\text { exigência }\end{array}$ & $\begin{array}{c}\text { Quantidade absorvida } \\
\text { em relação à máxima }\end{array}$ \\
\hline \hline \multirow{2}{*}{ cobre } & folhas & 61 & 45 \\
& caule & 61 & 47 \\
manganês & folhas & 67 & 48 \\
& caule & 69 & 52 \\
zinco & folhas & 62 & 47 \\
\hline
\end{tabular}

Observa-se que a absorção desses nutrientes pelas folhas ocorreu em igual intensidade, nessa época.

Embora se sabendo que o efeito das idades dentro dos órgãos estudados foi semelhante quanto à absorção do boro, efetuou-se a análise de regressão a fim de se determinar a época de maior exigência desses órgãos do nutriente e a de extração máxima, através das curvas de absorção obtidas. Observa-se pela Figura 3 que as curvas para os três órgãos foram iguais, como era de se esperar, obedecendo a regressão cúbica, mas as épocas em estudo foram diferentes.

A extração máxima de boro pelos órgãos ocorreu na faixa dos 100 a 111 dias e a época de maior exigência no periodo de 68 a 78 dias.

Em relação ao valor máximo (100\%), a quantidade absorvida pelos órgãos foi: folha, $46 \%$; caule, $44 \%$ e fruto, $47 \%$.

Quanto ao ferro, as curvas de absorção pelos órgãos foram lineares (Figura 3). Sendo a hortaliça considerada planta exigente em ferro, presume-se que o nutriente tenha sido absorvido e translocado até quase o final do ciclo. $O$ término do período experimental não coincidiu com o final do ciclo da cultura, não podendo ser observado porisso, o possível decréscimo da concentração do nutriente nas folhas, decorrente da intensidade do processo de translocação para os frutos.

Pelo Quadro 5 observa-se que o ferro, seguido do manganês e zinco foram os nutrientes que apresentaram as maiores concentrações nos órgãos em estudo.

SILVA et alii (1970), estudando a absorção de nutrientes pela cultura do alho, encontraram na época dos 90 a 105 dias para a parte aérea, concentrações de micronutrientes, na seguinte ordem decrescente: cobre, boro, ferro, zinco, sendo a menor a de manganês.

Para se ter idéia da quantidade de molibdênio absorvida pela parte aérea da planta, procedeu-se à análise apenas na amostragem correspondente aos 90 dias, em época de colheita para fins comerciais (Quadro 6). 


\begin{tabular}{lcc}
\hline Órgão & & Dias \\
\cline { 2 - 3 } & Ponto de inflexão & Ponto de máxima \\
\hline \hline folha & 69 & 100 \\
caule & 68 & 101 \\
fruto & 78 & 111 \\
\hline
\end{tabular}

SANTOS et alii (1972) trabalhando com plantas de ervilha, encontraram aos 90 dias, teores de molibdênio entre $0,5 \mathrm{ppm}$ a $1,3 \mathrm{ppm}$ para as folhas; $1,9 \mathrm{ppm}$ a 4,2 ppm para o caule e $1,4 \mathrm{ppm}$ a $2,7 \mathrm{ppm}$ para as vagens. Já as concentrações do elemento obtida por COSTA et alii (1972) em quiabeiro foram muito mais altas.

QUADRO 5 - Teores em ppm dos micronutrientes contidos na matéria seca dos órgãos estudados, em função da idade da planta.

\begin{tabular}{|c|c|c|c|c|c|c|c|}
\hline \multirow{2}{*}{$\begin{array}{l}\text { Idade da } \\
\text { planta } \\
\text { (dias) }\end{array}$} & \multirow{2}{*}{ Órgão } & \multicolumn{6}{|c|}{ Nutrientes } \\
\hline & & $\mathrm{B}$ & $\mathrm{Cu}$ & $\mathrm{Fe}$ & $\mathrm{Mn}$ & $\mathrm{Zn}$ & Mo \\
\hline \multirow{3}{*}{30} & folha & 59 & 25 & 568 & 144 & 94 & \\
\hline & caule & 59 & 30 & 302 & 91 & 81 & \\
\hline & fruto & - & - & - & - & - & \\
\hline \multirow{3}{*}{45} & folha & 41 & 16 & 1088 & 145 & 83 & \\
\hline & caule & 68 & 17 & 1004 & 64 & 81 & \\
\hline & fruto & - & - & - & - & - & \\
\hline \multirow{3}{*}{60} & folha & 38 & 15 & 370 & 213 & 119 & \\
\hline & caule & 42 & 16 & 257 & 158 & 68 & \\
\hline & fruto & 36 & 16 & 333 & 172 & 108 & \\
\hline \multirow{3}{*}{75} & folha & 50 & 22 & 402 & 396 & 149 & \\
\hline & caule & 65 & 25 & 306 & 192 & 76 & \\
\hline & fruto & 45 & 22 & 365 & 230 & 114 & \\
\hline \multirow{3}{*}{90} & folha & 66 & 15 & 364 & 297 & 139 & 0,83 \\
\hline & caule & 56 & 12 & 158 & 112 & 55 & 0,58 \\
\hline & fruto & 53 & 18 & 275 & 138 & 66 & 1,39 \\
\hline \multirow{3}{*}{105} & folha & 63 & 14 & 632 & 388 & 109 & \\
\hline & caule & 46 & 10 & 425 & 80 & 53 & \\
\hline & fruto & 18 & 10 & 333 & 219 & 60 & \\
\hline \multirow{3}{*}{120} & folha & 43 & 13 & 1243 & 476 & 103 & \\
\hline & caule & 38 & 8 & 486 & 112 & 63 & \\
\hline & fruto & 18 & 13 & 376 & 130 & 54 & \\
\hline
\end{tabular}




\section{Exportação de nutrientes}

Embora a colheita do espinafre Nova Zelândia para fins comerciais ocorra aproximadamente a partir dos 75 dias, para avaliar as quantidades médias totais de nutrientes exportados pela parte aérea da planta, considerou-se a amostragem dos 90 dias, tendo em vista o bom desenvolvimento da hortaliça nesse período, que coincidiu com a faixa de extração máxima de alguns dos nutrientes pelas folhas e caule.

Considerando-se uma população de 22.222 plantas por hectare, calculou-se também a extração aproximada em $\mathrm{kg}$ por hectare para os macronutrientes e g por hectare para os micronutrientes (Quadro 5).

ZINK (1965) em estudo sobre a nutrição mineral do espinafre, encontrou maiores quantidades de nutrientes removidas pela parte aérea da planta, na época da colheita, em relação às obtidas neste experimento. São os seguintes os dados em $\mathrm{kg} / \mathrm{ha}{ }^{*}$ encontrados pelo autor: 180 de nitrogênio; 22 de fósforo; 289 de potássio; 38 de cálcio e 41 de magnésio.

Resultados de experimentos de adubação com espinafre conduzidos por ROMAINE (1940) e WOLF \& ICHISAKA (1947) mostraram que a absorção de nitrogênio, fósforo e potássio pela parte aérea da planta em $\mathrm{kg} / \mathrm{ha}$ * ocorreu na faixa compreendida eníre 50 a 123 para nitrogênio; 5,60 a 14 para o fósforo e 41 a 105 para potássio. Em comparação com as quantidades obtidas presentemente, observa-se uma certa correspondência de dados.

QUADRO 6 - Quantidades médias totais de nutrientes extraídos pela parte aérea de uma planta de espinafre com 90 dias de idade.

\begin{tabular}{lrr}
\hline Nutrientes & \multicolumn{2}{c}{ Extração } \\
\hline & mg/planta & $\mathrm{kg} / \mathrm{ha}$ \\
\cline { 2 - 2 } nitrogênio (N) & 1767 & 39,7 \\
fósforo (P) & 209 & 4,7 \\
potássio (K) & 5430 & 120,6 \\
cálcio (Ca) & 1114 & 24,8 \\
magnésio (Mg) & 718 & 16,0 \\
enxofre (S) & 256 & 5,7 \\
& & \\
boro (B) & $\mu \mathrm{g} /$ planta & $\mathrm{g} / \mathrm{ha}$ \\
cobre (Cu) & 6725 & 149,4 \\
ferro (Fe) & 1548 & 34,4 \\
manganês (Mn) & 26678 & 3893,4 \\
zinco ( $\mathrm{Zn})$ & 20798 & 462,2 \\
molibdênio (Mo) & 7531 & 147,9 \\
\hline
\end{tabular}

* Dados recalculados. 


\section{CONCLUSÕES}

- A máxima produção de matéria seca das folhas ocorre aos 93 dias e a época de maior exigência da cultura corresponde aos 63 dias.

- A produção de matéria seca do caule e dos frutos tem um aumento contínuo até os 120 dias.

- A época de extração máxima dos nutrientes pelas folhas está entre 93 dias a 106 dias.

- A absorção do ferro (Fe) pelos órgãos é contínua até a última amostragem.

- Os teores percentuais dos macronutrientes e em partes por milhão dos micronutrientes absorvidos pelas folhas, aos 90 dias são: N- 2,54\%; P- 0,21\%; K- 5,65\%; Ca- 1,06\%; Mg- 0,83\%; S- 0,35\%; B- 66 ppm; Cu- 15 ppm; Fe- 364 ppm; M- 297 ppm; Zn- 139 ppm e Mo- 0,83 ppm.

- As quantidades extraídas pela parte aérea da planta aos 90 dias são:

\begin{tabular}{lcr}
\hline \multirow{2}{*}{ Nutrientes } & \multicolumn{2}{c}{ Extração } \\
\cline { 2 - 3 } & $\mathrm{mg} /$ planta & $\mathrm{kg} / \mathrm{ha}$ \\
\hline \hline nitrogênio $(\mathrm{N})$ & 1767 & 39,7 \\
fósforo $(\mathrm{P})$ & 209 & 4,7 \\
potássio $(\mathrm{K})$ & 5430 & 120,6 \\
cálcio (Ca) & 1114 & 24,8 \\
magnésio (Mg) & 718 & 16,0 \\
enxofre (S) & 256 & 5,7 \\
& & $\mathrm{~g} / \mathrm{ha}$ \\
boro (B) & Mg/planta & 149,4 \\
cobre (Cu) & 6725 & 34,4 \\
ferro (Fe) & 1548 & 592,8 \\
manganês (Mn) & 26678 & 462,2 \\
zinco (Zn) & 20798 & 147,9 \\
molibdênio (Mo) & 7531 & 2,2 \\
\hline
\end{tabular}


MINERAL NUTRITION OF VEGETABLE CROPS. XXVI - MINERAL NUTRITION OF NEW ZEALAND SPINACH (Tetragonia expansa MURR.): ABSORPTION OF MACRO AND MICRONUTRIENTS

Spinach plants were cultivated under field conditions. All manegement practice were observed. Periodically plants were harvested and analysed for $\mathrm{N}, \mathrm{P}, \mathrm{K}, \mathrm{Ca}, \mathrm{Mg}, \mathrm{S}$, $\mathrm{B}, \mathrm{Cu}, \mathrm{Fe}, \mathrm{Mn}$, Mo and $\mathrm{Zn}$.

- The variety presented a continuous growth expressed, in dry matter, until 120 days.

- The greatest demand for nutrients occurs between 93 and 106 days.

- The maximum absorption of the nutrients by leaves is around the period of 93 to 106 days.

- The absorption of Fe by the spinach plants is continuous until at the end of the plant life.

- At 90 days the spinach leaves presented the following concentration: $N$ - $2.54 \%$; P- 0.21\%; K- 5.64\%; Ca- 1.06\%; Mg- 0.83\%; S- 0.35\%; B- 66 ppm; Cu- 15 ppm; Fe- 364 ppm; Mn- 297 ppm; Zn- 139 ppm and Mo- 0.83 ppm.

- One plant and 22,222 spinach plants (one ha.) remove the following quantities in nut rients:

\begin{tabular}{crr}
\hline \multirow{2}{*}{ Nutrient } & \multicolumn{2}{c}{ Removed } \\
\cline { 2 - 3 } & $\mathrm{mg} / \mathrm{plant}$ & $\mathrm{kg} / \mathrm{ha}$ \\
\hline $\mathrm{N}$ & 1,767 & 39.7 \\
$\mathrm{P}$ & 209 & 4.7 \\
$\mathrm{~K}$ & 5,430 & 120.6 \\
$\mathrm{Ca}$ & 1,114 & 24.8 \\
$\mathrm{Mg}$ & 718 & 16.0 \\
$\mathrm{~S}$ & 256 & 5.7 \\
& & $\mathrm{~g} / \mathrm{ha}$ \\
$\mathrm{Bg}$ & 6,725 & 149.4 \\
$\mathrm{Cu}$ & 1,548 & 34.4 \\
$\mathrm{Fe}$ & 26,678 & 592.8 \\
$\mathrm{Mn}$ & 20,798 & 462.2 \\
$\mathrm{Zn}$ & 7,531 & 147.9 \\
$\mathrm{Mo}$ & 98 & 2.2 \\
\hline
\end{tabular}




\section{LITERATURA CITADA}

BARADI, T.A. \& SHAFIE, A.L., 1963. Note on the phosphorus uptake by some vegetables during growth as studied by ${ }_{32}$ P. J. Bot. Un. Arab. Repub., 6:105-114. Apud Soils and Fertilizers, $29: 285,1966$.

BEAR, F.E. \& TOTH, S.J., 1948. Influence of calcium on availability of other soils cations. Soil Sci., $65.69-74$. •

BOAWN, L.C., 1971. Zinc accumulation characteristics of some leafy vegetables. Comm. Soil Sci. Pl. Anal., 2(1):31-36.

CATANI, R.A. \& JACINTHO, A.O., 1974. Análise química para avaliar a fertilidade do solo. Boletim Didático no 37, E.S.A. "Luiz de Queiroz", USP, Piracicaba, São Paulo.

COBRA NETTO, A., ACCORSI, W.R. \& MALAVOLTA, E., 1971. Estudos sobre a nutrição mineral do feijoeiro (Phaseolus vulgaris L. var. Roxinh). Anais da E.S.A. "Luiz de Queiroz", USP, 28:257-274.

COSTA, M.C.B., HAAG, H.P. \& SARRUGE, J.R., 1972. Nutrição mineral de hortaliças. Absorção de macro e micronutrientes pela cultura do quiabeiro (Hibiscus esculentum L.). Anais da E.S.A. "Luiz de Queiroz", 29:109-126.

FERNANDES, P.D., OLIVEIRA, G.D. de \& HAAG, H.P., 1971. Nutrição mineral de hortaliças. XIV. Absorção de macronutrientes pela cultura da alface. O Solo, 63(2):7-10.

FERNANDES, P.D. \& HAAG, H.P., 1972. Nutrição mineral de hortaliças. XXI. Efeito da omissão dos macronutrientes no crescimento e na composição química do pimentão (Capsicum annuum L.). var. Avelar. Anais da E.S.A. "Luiz de Queiroz", 29:223-235.

FILGUEIRA, F.A.R., 1972. Manual de olericultura: cultura e comercialização de hortaliças. Agronômica Ceres, São Paulo.

GERALDSON, C.M., KLACAN, G.R. \& LORENZ, O.A., 1973. Plant analysis as an aid in fertilizing vegetable crops. pp. 365-380. IN : L.M. Walsh \& J.D. Beaton (eds.). Soil testing and plant analysis. Wisconsin, USA.

GOODALL, D.W., 1946. The distribution of weight change in the young tomato plants. Changes in dry weight of separated organs and translocations rates. Ann. of Bot., 10(40):305-338.

HOMA, P., HAAG, H.P. \& SARRUGE, J.R., 1969. Nutrição mineral de hortaliças. II. Absorção de nutrientes pela cultura de couve-flor. O Solo, 61(1):9-16.

KNOTT, J.E., 1950. Potherbs or greens. pp. 164-170. IN: Lea \& Febiger (eds.). Vegetable growing. 4th ed. Philadelphia, USA.

PEARL, R., EDUARD, T.I. \& MINEE, J.R., 1934. The growing of Cucunis melo L. seedlings at different temperatures. J. Gen. Physiol., $17: 687-700$.

PETERSON, W.H., SKINNER, J.T. \& STRONG, F.M., 1945. Vitamin content of common foods. pp. 272-277. IN: Element of food biochemistry Prentice-Hall, Inc., New York, New York.

ROMAINE, J.D., 1940. Consider plants foods content of crops. Better Crops, 3:6-42.

SANTOS, M.A.C., HAAG, H.P. \& SARRUGE, J.R., 1972. Nutrição mineral de hortaliças. XX. Absorção de macro e micronutrientes pela ervilha (Pisum sativum L.). Anais da E.S.A. "Luiz de Queiroz", $29: 127-144$.

SARRUGE, J.R. \& HAAG, H.P., 1974. Análises químicas em plantas. Departamento de Química, E.S.A. "Luiz de Queiroz", USP, Piracicaba, São Paulo.

SARRUGE, J.R., GOMES, L., HAAG, H.P. \& MALAVOLTA, E., 1963. Estudos sobre a alimentação mineral do algodoeiro. I. Marcha de absorção de macronutrientes. Anais da E.S.A. "Luiz de Queiroz", 20:13-23.

SCHWIETZER, C.H., 1963. Der einsenreiche spinat. Nutr. Abstr., 33:40. 
SILVA, N. da, OLIVEIRA, G.D. de, VASCONCELlOS, E.F.E. \& HAAG, H.P., 1970. Nutrição mineral de hortaliças. XI. Absorção de nutrientes pela cultura do alho. Solo, 62:7-17.

SILVEIRA, R.I., MELLO, F.A. de, BRASIL SOBRo, M.O.C. \& ARZOLLA, S., 1971. Adubos e Adubação das principais culturas brasileiras. Vol. II. Depto. de Solos e Geologia, E.S.A. "Luiz de Queiroz", USP, Piracicaba, São Paulo.

TASHIRO, I. \& INARI, S., 1964. Food chemical studies on leaf vegetables. I. On mineral of tsuruna. J. Jap. Soc. Food. Nutr., 17:102-105. Apud Nutr. Abstr., 35 :333 (1965).

WOLF, B. \& ICHISAKA, V., 1947. Rapid chemical soil and plant tests. Soil Sci., 64:227-244.

ZINK, F.W., 1965. Growth and nutrient absorption in spring spinach. Proc. Amer. Soc. Hort. Sci., 87:380-386. 